\title{
Spatial variations in the distribution of yearling spring Chinook salmon off Washington and Oregon using COZIGAM analysis
}

\author{
Hao $\mathrm{Yu}^{1, *}$, Hongsheng $\mathrm{Bi}^{1}$, Brian Burke ${ }^{2}$, Jesse Lamb ${ }^{3}$, William Peterson ${ }^{3}$ \\ ${ }^{1}$ Chesapeake Biological Laboratory, University of Maryland Center for Environmental Science, Solomons, Maryland 20688, USA \\ ${ }^{2}$ NOAA Fisheries, Northwest Fisheries Science Center, Seattle, Washington 98112, USA \\ ${ }^{3}$ NOAA Fisheries Newport Station, Hatfield Marine Science Center, Newport, Oregon 97365, USA
}

\begin{abstract}
Yearling Chinook salmon Oncorhynchus tshawytscha were sampled off Washington and Oregon, USA, along with environmental factors, every June from 1998 to 2010. The abundance of yearling Chinook salmon varied over space with a high proportion of zero catches. Positive catches were more numerous north of the Columbia River, likely because most yearling Chinook salmon turn north after leaving the Columbia River. Using the latitude of the Columbia River mouth as a geographical border, the survey area was divided into 2 regions: north and south of the Columbia River. We hypothesized that (1) the spatial distribution pattern within each region was related to local environmental factors and (2) the difference between north and south was related to largescale ocean processes. A constrained zero-inflated generalized additive model (COZIGAM) was applied to examine the non-linear relationships between juvenile salmon abundance and environmental factors. Results from the COZIGAM suggested that water temperature, chlorophyll a (chl a) concentration, copepod biomass and spatial factors were significantly correlated with the density of salmon in the northern region, and only chl a concentration was correlated significantly with yearling Chinook density in the southern region. The difference between the abundances north and south of the Columbia River was significantly correlated with alongshore ocean currents, with weaker alongshore currents leading to greater difference between north and south. Results suggest that salmon distribution is determined not only by standard habitat parameters (local biotic and abiotic factors) but by ocean conditions such as the strength of alongshore coastal currents.
\end{abstract}

KEY WORDS: Juvenile salmon · Yearling Chinook · Chlorophyll $\cdot$ Zero-inflated generalized additive model $\cdot$ Alongshore ocean current

- Resale or republication not permitted without written consent of the publisher

\section{INTRODUCTION}

Environmental factors often show complex nonlinear relationships with the distribution of fish species (Swartzman et al. 1992, Stoner et al. 2001, Ciannelli et al. 2008). To model the non-linear relationships, generalized additive models (GAMs) have been shown to perform better than commonly used generalized linear models (GLMs) (Wood 2006, Yu et al. 2011). While the Poisson distribution is often used to model count data (Cunningham \& Lindenmayer 2005), over-dispersion often becomes a major issue when the count data are zero inflated. Ignoring zero inflation can cause biased estimation of parameters and standard errors (Richards 2008), and, therefore, for survey data with many zeroes, zero-inflated distributions may be more appropriate (Lambert 1992, Hall 2000). A constrained zeroinflated generalized additive model (COZIGAM) has been developed to model the non-linear relationships for these types of data (Liu \& Chan 2010). In the present study, we developed a COZIGAM to understand the spatial and temporal distribution of juvenile Chinook salmon Oncorhynchus tshawyt- 
scha off Washington and Oregon, USA. This model has a large potential for studying the spatial pattern of salmon as well as other species.

Previous studies have revealed that local environmental factors can affect the life-history traits of salmon. For example, sea surface temperature (SST) is correlated with growth rate (Hinch et al. 1995), age of maturation (Friedland 1998), timing of migration (Metcalfe 1998, Dahl et al. 2004), marine production (Jonsson \& Jonsson 2004) and habitat use (Hinke et al. 2005). Chlorophyll a (chl a) concentration and zooplankton biomass also influence salmon distribution and production (Brodeur et al. 2004, Bi et al. 2007, 2011a). However, the preferences to the environmental factors are different among populations and even among different life stages (Kendall et al. 2010). Many studies have been conducted on salmon ecology; however, the general understanding of yearling Chinook salmon distribution is very limited (Trudel et al. 2009, Peterson et al. 2010, Tucker et al. 2011). In the present study, we focus on the variation in spatial distribution and how it is related to environmental factors.

The potential impact of large-scale ocean conditions on salmon has gained wide interest in recent years. The Pacific Decadal Oscillation (PDO) was reported to influence adult salmon catches in the Northeast Pacific Ocean (Mantua et al. 1997, Rupp et al. 2012), El Niño events influence the survival of salmon (Pearcy 1992), and strong correlation has been found between the Coastal Upwelling Index (CUI) and salmon survival (Nickelson 1986, Logerwell et al. 2003) (although the relationship between upwelling and salmon has since broken down). The mechanisms of these relationships are not completely understood. A general perception is that changes in large-scale ocean conditions will cause variation in local environmental factors, such as water temperature, prey availability and prey quality (suggested by Hooff \& Peterson 2006), and these may in turn affect salmon survival and production in certain areas.

The distribution of yearling spring Chinook salmon shows spatial and interannual patterns along the coast off Washington and Oregon, USA (Peterson et al. 2010). In general, yearling Chinook salmon are more abundant along the Washington coast than along the Oregon coast (Pearcy \& Fisher 1990, Trudel et al. 2009, Peterson et al. 2010). The abundance of yearling Chinook salmon in trawl surveys also shows large interannual variation (Bi et al. 2007, Peterson et al. 2010). The spatial distribution pattern has been shown to correlate with large-scale ocean conditions and local environmental factors along the Washing- ton and Oregon coasts, such as strong upwelling, the PDO, chl a concentration, copepod biomass, water temperature and bathymetry (Brodeur et al. 2004, Bi et al. 2008, 2011a, Peterson et al. 2010). Understanding juvenile salmon spatial distribution in relation to its pelagic habitat is necessary for studying spatial variation of juvenile salmon growth and survival. However, analysis of spatial distribution can be challenging for 4 reasons: (1) the complexity of the physical processes affecting their spatial/temporal variations, (2) the relatively low density of juvenile Chinook salmon in the ocean, (3) the large proportion of zero catches in the survey data and (4) juvenile salmon are often spatially autocorrelated, i.e. aggregative in certain areas. These problems are not unique to salmon but also apply to other aquatic species (Minami et al. 2007, Arab et al. 2008).

All previous studies (Bi et al. 2007, 2008, Peterson et al.2010, Pool et al. 2012) are based on the premise that both large-scale ocean conditions and local habitat characteristics could affect where juvenile Chinook salmon reside. However, none of the previous studies have properly addressed spatial autocorrelation, except Bi et al. (2011a) where random effects were considered as spatial structure. Without properly addressing spatial autocorrelation, models may produce dubious relationships (Latimer et al. 2006, Beale et al. 2010). Therefore, it is necessary to test spatial autocorrelation patterns and develop new models that can address spatial autocorrelation; here we investigate use of the COZIGAM. The objectives of this study were to: (1) understand spatial and temporal variations of juvenile Chinook salmon density, (2) characterize salmon density using environmental and spatial factors, and (3) examine the relationship between salmon spatial distribution and large-scale ocean conditions using alongshore currents as a proxy.

\section{MATERIALS AND METHODS}

\section{Study area and data collection}

Yearling spring Chinook salmon Oncorhynchus tshawytscha were sampled with a pelagic rope trawl (NET Systems, Nordic 264) off Washington and Oregon in June from 1998 to 2010, along 9 transects and 6 to 10 stations along each transect (Fig. 1). The trawl net was $100 \mathrm{~m}$ long with a $30 \times 20 \mathrm{~m}$ mouth opening, and $0.8 \mathrm{~cm}$ mesh size at the cod-end. At each location, the upper $20 \mathrm{~m}$ water column was sampled in tows over a distance of approx. $3 \mathrm{~km}$. Salmon density was estimated as number of fish caught per tow. Chi- 


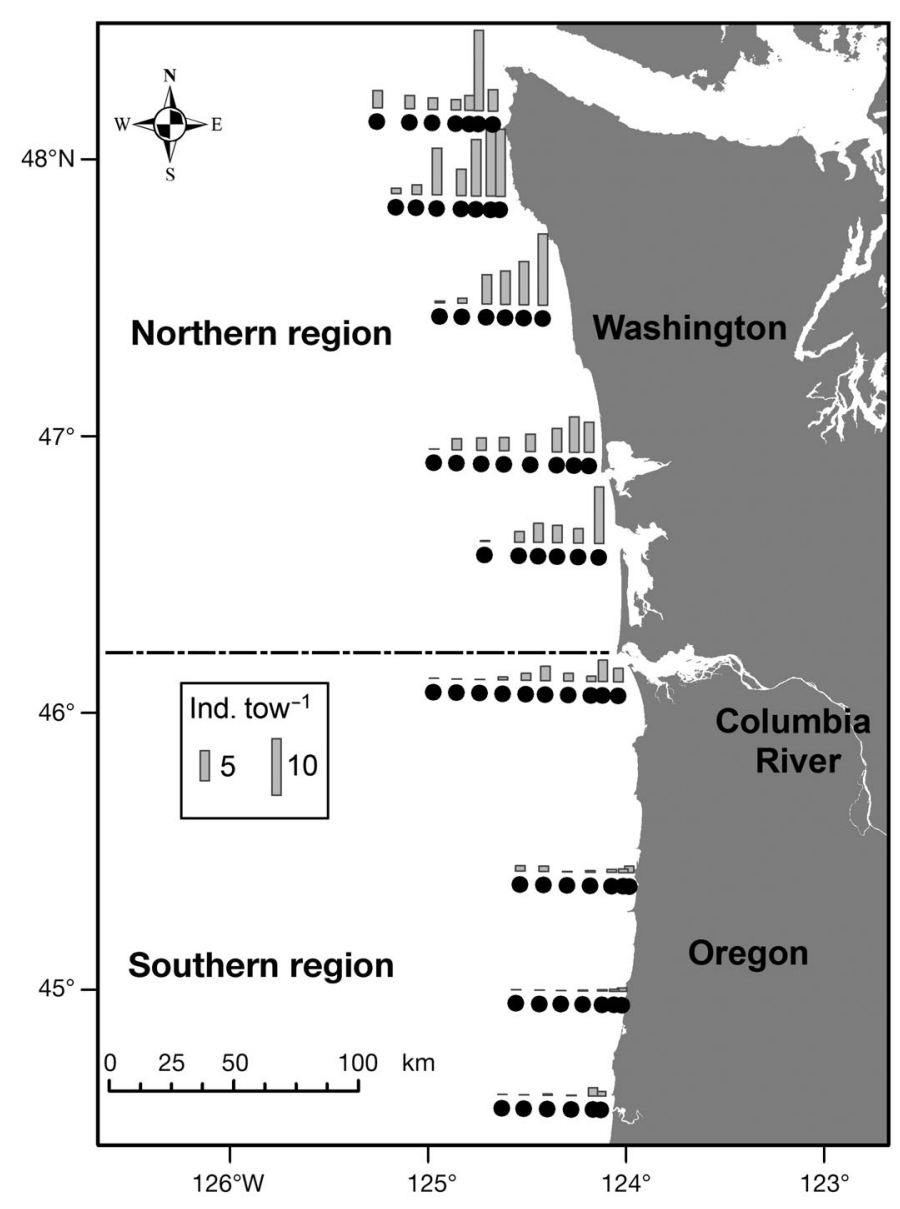

Fig. 1. Locations of juvenile spring Chinook salmon Oncorhynchus tshawytscha surveys (dots) off Washington and Oregon and the mean density of salmon at each sampling location (ind. caught per tow, bars) in June from 1998 to 2010

nook salmon with fork lengths between 141 and $280 \mathrm{~mm}$ were considered yearlings (Peterson et al. 2010). Habitat parameters were also recorded at each sampling location (Table 1). We calculated a mean alongshore current velocity within $1^{\circ}$ of the coast at the latitude of the Columbia River mouth $\left(46.2^{\circ} \mathrm{N}\right)$ using satellite altimeter and coastal sea level data (following Saraceno et al. (2008)). For details of sampling methods of environmental factors, see Bi et al. (2007) and Peterson et al. (2010).

\section{Data analysis}

Moran's I (Moran 1950) was used to examine spatial autocorrelation of the salmon survey data. The function to estimate Moran's $I$ is:

$$
I=\frac{n}{(n-1) S^{2} h} \sum_{i=1}^{n} \sum_{j=1}^{n} h_{i j}\left(Y\left(t_{i}\right)-\bar{Y}\right)\left(Y\left(t_{j}\right)-\bar{Y}\right)
$$

Table 1. Habitat parameters available from juvenile spring Chinook salmon Oncorhynchus tshawytscha surveys off Washington and Oregon

\begin{tabular}{|c|c|}
\hline Variables & Remarks \\
\hline Longitude $\left({ }^{\circ}\right)$ & $\begin{array}{l}\text { Converted to NAD } \\
1983 \text { UTM } 10 \mathrm{~N}\end{array}$ \\
\hline Latitude $\left({ }^{\circ}\right)$ & $\begin{array}{l}\text { Converted to NAD } \\
1983 \text { UTM 10N }\end{array}$ \\
\hline Water depth (m) & Per sampling site \\
\hline Water temperature $\left({ }^{\circ} \mathrm{C}\right)$ & $3 \mathrm{~m}$ below surface \\
\hline Chl a concentration $\left(\mathrm{mg} \mathrm{m}^{-3}\right)$ & $3 \mathrm{~m}$ below surface \\
\hline Copepod biomass (mg carbon $\mathrm{m}^{-3}$ ) & Per sampling site \\
\hline Salinity & Per sampling site \\
\hline
\end{tabular}

where $n$ is the number of observations, $Y\left(t_{i}\right)$ and $Y\left(t_{j}\right)$ are catch data at any 2 spatial locations $i$ and $j, \bar{Y}$ is the mean value of all observations, $S^{2}$ is the variance, and $h$ is the sum of inverse distance weights $h_{i j}$. If spatial autocorrelation is absent, the expected value of $I$ is $-1 /(n-1)$, which tends towards zero as $n$ increases. Significance of spatial autocorrelation was tested by transforming $I$ to $Z$-scores:

$$
Z=\frac{|I-E(I)|}{\sqrt{\operatorname{Var}(I)}}
$$

where $E$ indicates expectation and Var indicates variance. To calculate distances between observations, latitude and longitude were converted to the NAD 1983 UTM $10 \mathrm{~N}$ projected coordinate system, and the Euclidean distances were used. Directional Moran's I was also calculated in this study. North-south Moran's I indicated that only the spatial points located at a similar longitude $(<10 \mathrm{~km})$ were correlated; similarly, west-east Moran's I was used for the spatial points at a similar latitude $(<2 \mathrm{~km})$.

The zero-inflated Poisson distribution is a mixture of 2 distributions, a degenerate component that is zero with certainty and a second component that includes zeros and positive values (i.e. the Poisson distribution). The general form of this distribution is:

$$
\operatorname{Pr}(Y=k)=\left\{\begin{array}{cl}
\omega+(1-\omega) \exp (-\lambda) & k=0 \\
\frac{(1-\omega) \exp (-\lambda) \lambda^{k}}{k !} & k>0
\end{array}\right.
$$

where $k$ is the number of occurrences, $\lambda$ is the mean of the observations from the non-zero-inflation part, and $\omega$ is the probability that an observation comes from the degenerate component (Maunder \& Punt 2004). Since the zero-inflated Poisson distribution is divided into 2 components, a non-zero-inflation part and a zero-inflation part, the data can be analyzed using a 
COZIGAM (Liu \& Chan 2010). We developed separate COZIGAMs for the northern and southern regions because the densities of juvenile spring Chinook salmon and the characteristics of their habitats were quite different in these 2 regions. The non-zero-inflation part was modeled using a GAM (Wood 2006):

$$
\begin{aligned}
g(\mu) & =\alpha+s\left(\text { temperature }, k_{1}\right)+s\left(\text { chlorophyll }, k_{2}\right) \\
& +s\left(\text { copepods }, k_{3}\right)+s\left(\text { depth }, k_{4}\right)+s\left(\text { salinity }, k_{5}\right) \\
& +s\left(\text { longitude } \times \text { latitude }, k_{6}\right)
\end{aligned}
$$

where $\alpha$ is the intercept, $g$ is a log link, $\mu$ is the expectation of observations, $s$ is a smoothing function, and $k_{1}$ to $k_{6}$ are the numbers of knots for smoothing functions. The zero-inflation part is modeled with a logistic regression model:

$$
\operatorname{logit}(\omega)=c+\delta \cdot g(\mu)
$$

where $c$ is an estimated parameter, $\delta=\left(\delta_{1}, \delta_{2}, \delta_{3}, \delta_{4}\right.$, $\left.\delta_{5}, \delta_{6}\right)^{\mathrm{T}}$ is a vector consisting of 6 coefficients, each associated with a single smooth function, and $\mathrm{T}$ is the transpose of a vector. The parameters in COZIGAM were estimated using a penalized likelihood method (Liu \& Chan 2010). The marginal likelihood method was used to choose the predictor variables in both the non-zero-inflation part and zero-inflation part of the COZIGAM. At first we chose water temperature, chl a concentration, copepod biomass, salinity, water depth and spatial factors as available predictor variables based on a literature review. All possible covariate combinations were used to build candidate models. Those models that could not converge or could converge but with non-significant coefficients were eliminated. Then the marginal likelihood was calculated for each optional model. The model with the highest marginal likelihood was selected as the final model. The expectation and variance of each observation were estimated as:

$$
\begin{gathered}
E\left(Y_{i}\right)=\mu_{i} \times\left(1-\omega_{i}\right) \\
\operatorname{var}\left(Y_{i}\right)=\left(1-\omega_{i}\right) \times\left(\mu_{i}+\omega_{i} \times \mu_{i}^{2}\right)
\end{gathered}
$$

The effect of each predictor variable was the prediction of the smooth function s(predictor) in the COZIGAM. The absolute value of the effect was used to measure the relative importance of the predictor variables in the model. The number of knots is often restricted to 4 for a single covariate (Yu et al. 2011). In Eqs. (4) \& (5), the number of knots was predetermined ( $k_{1}$ to $k_{5}=4, k_{6}=20$ ) in order to avoid over-fitting. The fitted salmon density in each year was estimated by:

$$
P_{Y}=\frac{\sum_{i=1}^{n_{y}} E\left(Y_{i, Y}\right)}{n_{Y}}
$$

where $E\left(Y_{i, Y}\right)$ is the expectation of observation $i$ in year $y$ and $n_{y}$ is the number of observations in year $y$. And its variance was:

$$
V_{Y}=\frac{\sum_{i=1}^{n_{Y}}\left(E\left(Y_{i, Y}\right)-P_{Y}\right)^{2}}{n_{Y}-1}
$$

The fitted salmon density and its variance in each transect were estimated using a similar equation by replacing time scale with spatial scale. We initially applied the COZIGAM model to the full data, but the model did not converge due to the increasing zero observations from north towards south. Thus, we applied the model to north and south of the Columbia River separately. Note that most juvenile salmon in the study area were from the Columbia River, and they typically migrated north after they were released into the ocean.

As will be shown below, we found differences in distributions between the northern and southern regions. We tested the hypothesis that the differences were related to the alongshore current by using cumulative current speed in the period from April to June. These data and the methods by which they were calculated are from Bi et al. (2011b). Positive accumulated alongshore ocean current speed indicated that the current flowed from the California coast to the Washington and Oregon coast, and vice versa. A simple linear model was used to analyze the relationship between 3 mo accumulated alongshore ocean current speed and the log-transformed ratio of fish densities in the northern and southern regions. All analyses were conducted using $\mathrm{R}$ software (v. 2.11.1; http://www.r-project.org).

\section{RESULTS}

The catch (Oncorhynchus tshawytscha density) data were highly zero-inflated in both the northern and southern regions (Fig. 2). The proportion of zero catches among total catches was $35.8 \%$ in the northern region and $63.0 \%$ in the southern region. The overall mean density of yearling Chinook salmon in the entire study area was $3.5 \pm 7.6$ ind. tow ${ }^{-1}$ (mean \pm SD) in June from 1998 to 2010. The density in the northern region was $5.7 \pm 9.8$ ind. tow ${ }^{-1}$, and the density in the southern region was $1.1 \pm 2.4$ ind. tow ${ }^{-1}$.

The density of yearling Chinook salmon and environmental factors varied over time but without a clear trend (Fig. 3). The density was highest in 2008 and lowest in 2005, followed by 1998. In most years, mean SSTs were around 12 to $14^{\circ} \mathrm{C}$. The warmest 


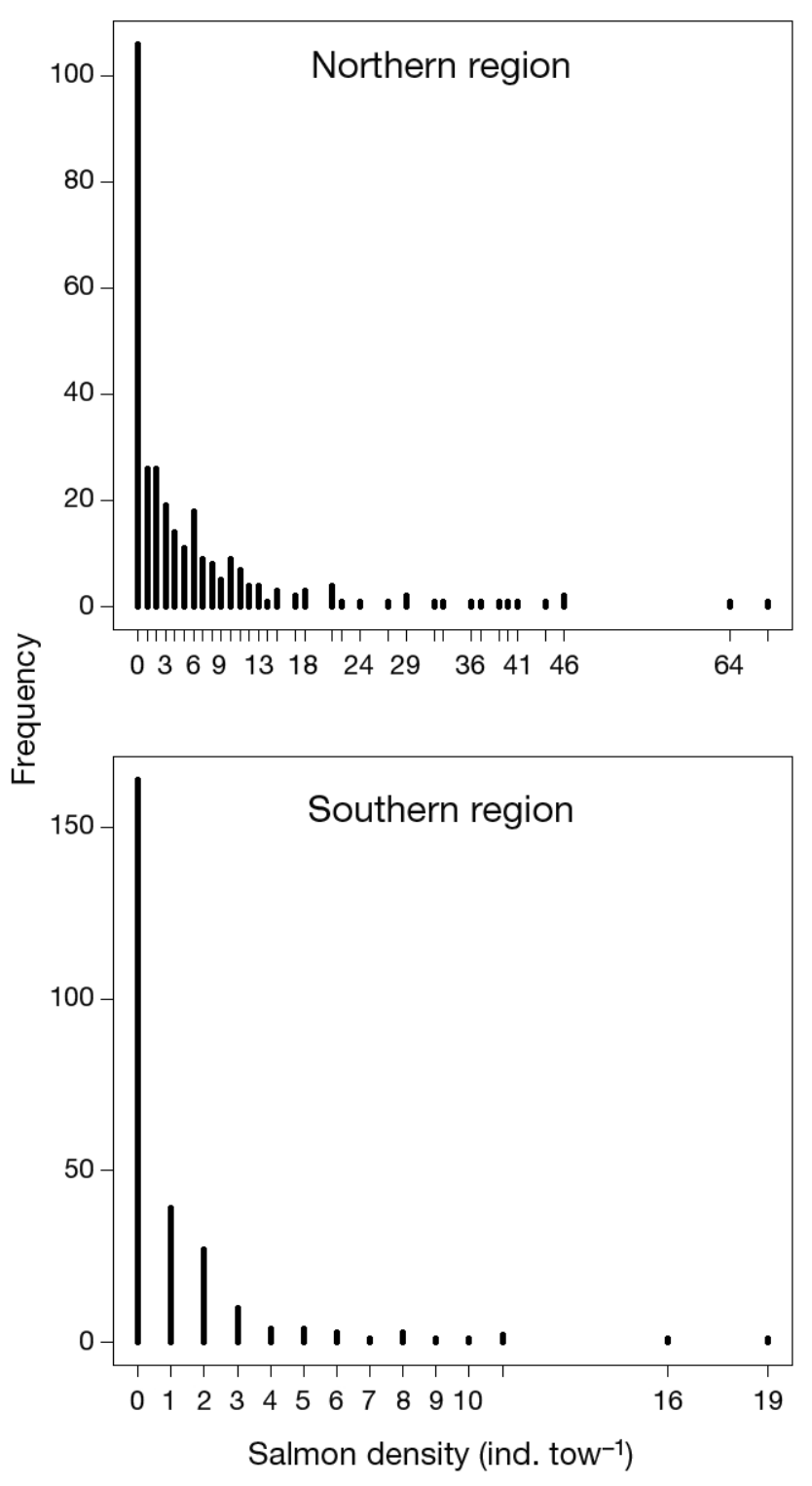

Fig. 2. Oncorhynchus tshawytscha. Frequency distribution of juvenile spring Chinook salmon density in regions (a) north and (b) south of the Columbia River mouth

year was 2005 (mean $=14.9^{\circ} \mathrm{C}$ ) and the coldest year was 2008 (mean $\left.=11.6^{\circ} \mathrm{C}\right)$. Copepod biomass and chl a concentration also exhibited high variability over time. The variation in chl a concentration in 2007 was higher than that in other years (SD = 18.4).

The density of yearling Chinook salmon showed a clear latitudinal pattern (Fig. 4). Densities increased with latitude up to $47.9^{\circ} \mathrm{N}$ and then decreased in the northernmost transect. Water temperature increased from 44.7 to $46.2^{\circ} \mathrm{N}$ and then decreased with increasing latitude. In general, copepod biomass decreased with increasing latitude. Chl a concentration
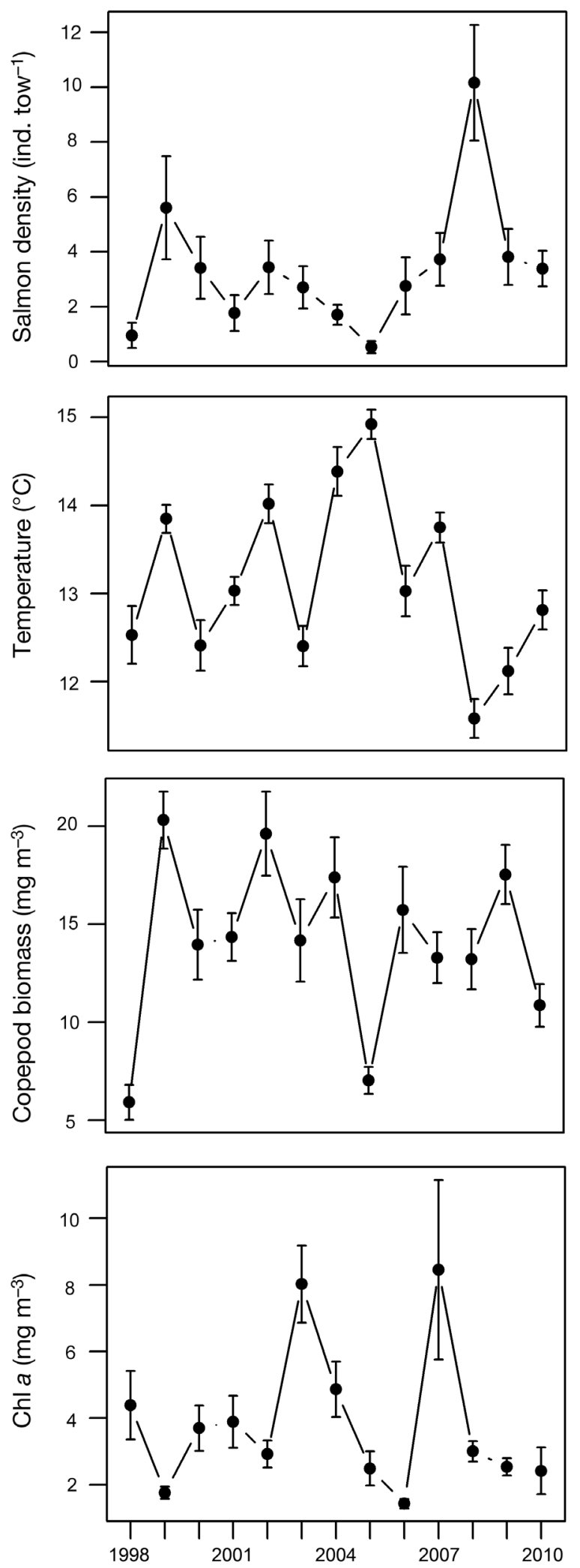

Fig. 3. Oncorhynchus tshawytscha. Mean $( \pm \mathrm{SE})$ density of juvenile spring Chinook salmon and mean $( \pm \mathrm{SE})$ values of environmental factors in June from 1998 to 2010 

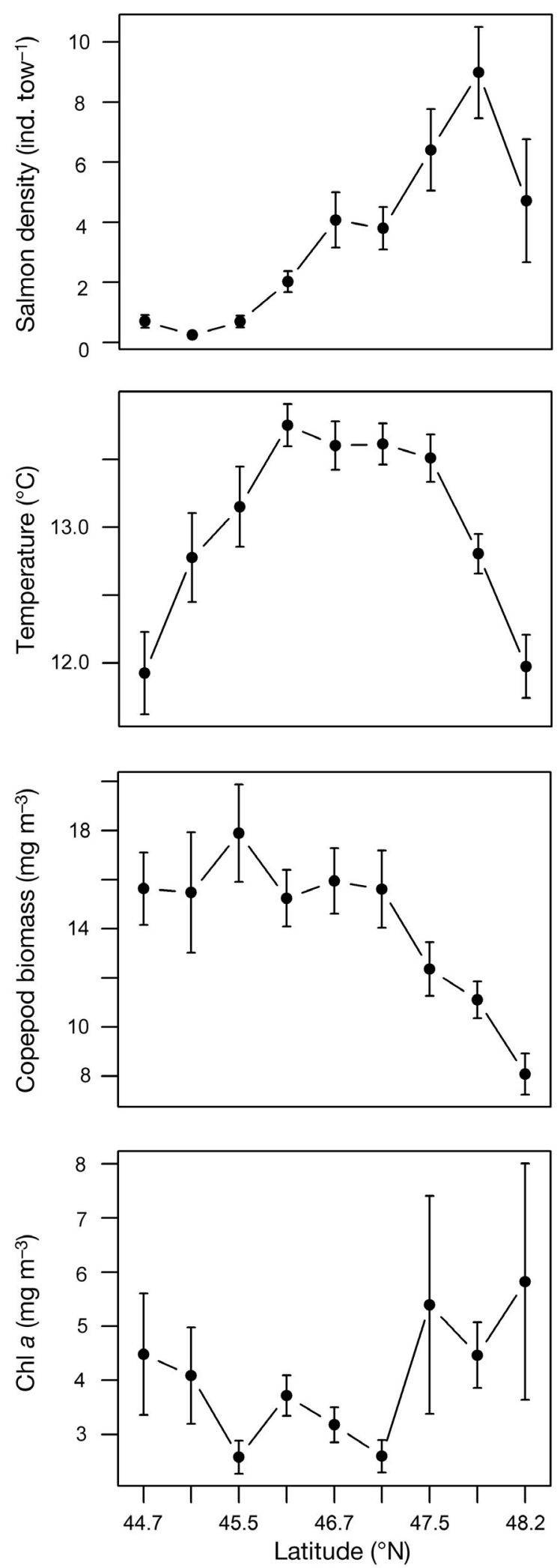

Fig. 4. Oncorhynchus tshawytscha. Mean $( \pm \mathrm{SE})$ density of juvenile spring Chinook salmon and $( \pm \mathrm{SE})$ mean values of environmental factors in each transect was on average higher (and more variable) in the north $\left(47.5\right.$ and $\left.48.2^{\circ} \mathrm{N}\right)$.

Using Z-scores of global Moran's $I$ and directional Moran's $I$, we found that significant spatial autocorrelation occurred in the distributions of yearling spring Chinook salmon in some years (Fig. 5) and that salmon displayed a different spatial pattern between the 2 regions. In the northern region, salmon showed significant spatial autocorrelation in 5 of the 13 years (1999, 2002, 2004, 2005 and 2010), but only in 3 years were salmon spatially autocorrelated in the southern region (2001, 2008 and 2009). Furthermore, the directional Moran's I tended to be consistent in an east-west (inshore-offshore) direction and northsouth direction in both regions, i.e. if spatial autocorrelation occurred in one direction, it also occurred in the other direction. The global Moran's I statistic was mainly determined by the south-north directional pattern in both the northern and southern regions (Fig. 5).

\section{Relationship between fish density and predictor variables}

For the non-zero-inflation part of the model, water temperature, copepod biomass, chl a concentration and spatial factors were significant in the northern region, and only chl a concentration in the southern region. For the zero-inflation part of the model, water temperature and copepod biomass were significant in the northern region, and chl $a$ in southern region. The coefficients of the COZIGAM on juvenile Chinook salmon density were estimated separately in the northern and southern regions (Tables $2 \& 3$ ). The

Table 2. Oncorhynchus tshawytscha. Coefficient estimates of the constrained zero-inflated generalized additive model (COZIGAM) on juvenile spring Chinook salmon density in the northern region. $\mathrm{p}<0.01$ for all results

\begin{tabular}{|c|c|c|c|}
\hline Coefficient & Estimate & $\mathrm{SE}$ & Statistical test \\
\hline Non-zero-inflated & & & $Z$ \\
\hline$\alpha$ & 1.71 & 0.05 & 37.96 \\
\hline & & & Chi-squared \\
\hline$s$ (temperature) & & & 99.05 \\
\hline$s(\mathrm{chl} a)$ & & & 94.55 \\
\hline$s($ copepod $)$ & & & 61.40 \\
\hline$s$ (longitude $\times$ latitude) & & & 288.05 \\
\hline Zero-inflated & & & $Z$ \\
\hline$C$ & 0.86 & 0.16 & 5.50 \\
\hline$\delta_{1}$ & 1.63 & 0.55 & 2.99 \\
\hline$\delta_{3}$ & 3.00 & 1.23 & 2.45 \\
\hline
\end{tabular}



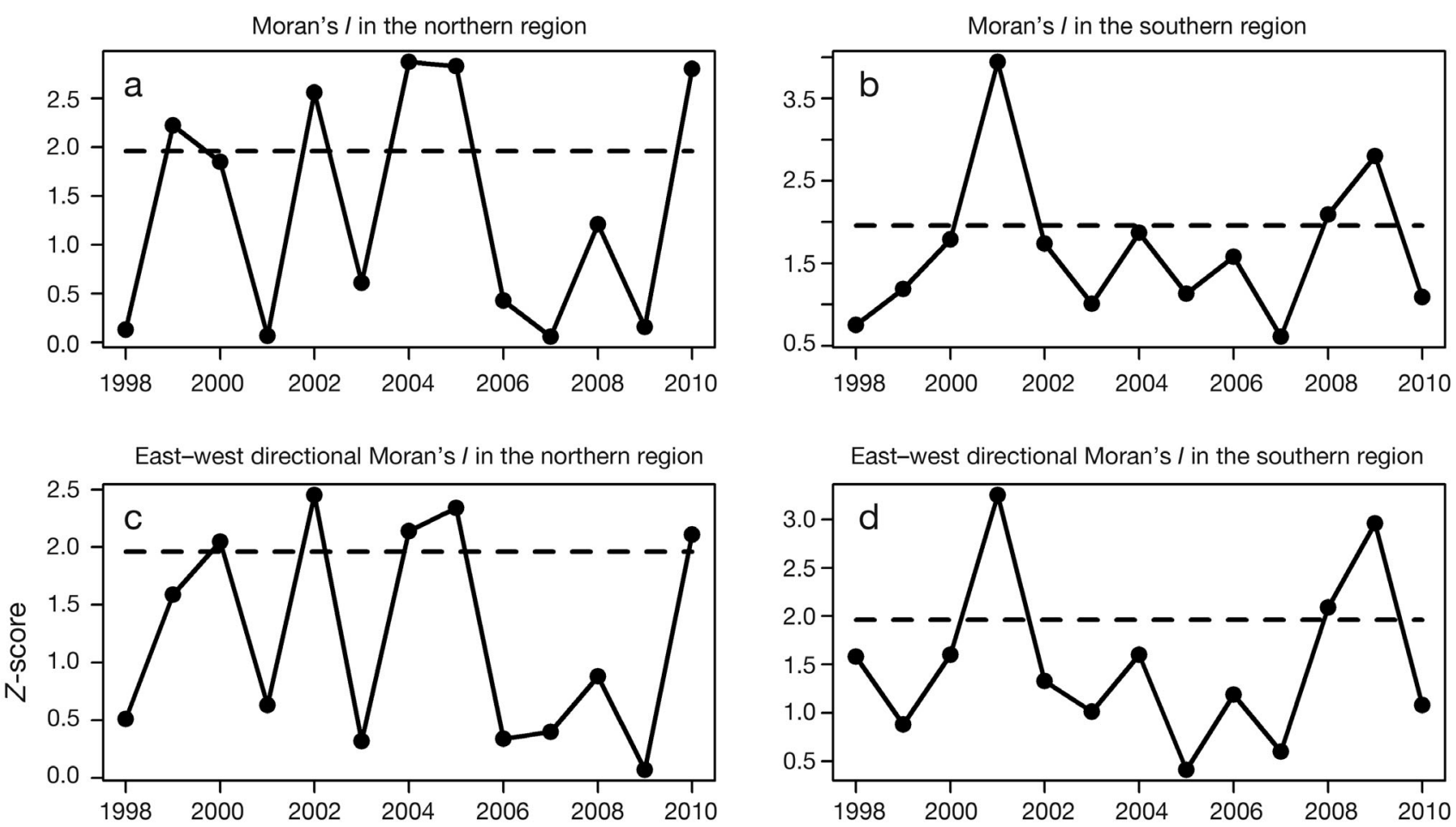

South-north directional Moran's / in the northern region

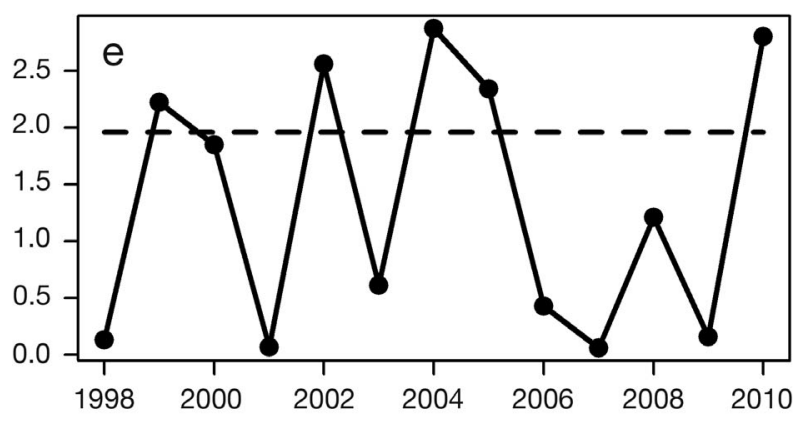

South-north directional Moran's / in the southern region

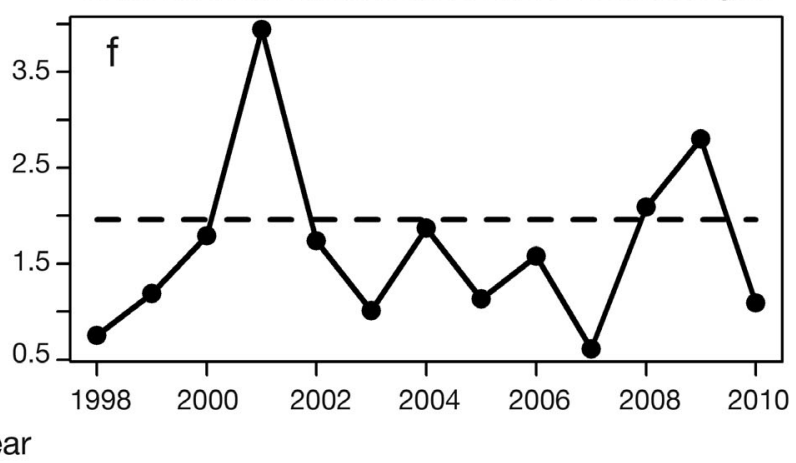

Fig. 5. Oncorhynchus tshawytscha. Z-scores relevant to global Moran's $I$ and directional Moran's $I$ values of juvenile spring Chinook salmon density over time. Dashed line: cutoff for significance

Table 3. Oncorhynchus tshawytscha. Coefficient estimates of the COZIGAM on juvenile spring Chinook salmon density in the southern region

\begin{tabular}{|lcccc|}
\hline Coefficient & Estimate & SE & Statistical test & $p$ \\
\hline Non-zero-inflated & & \multicolumn{4}{c}{} \\
$\alpha$ & 0.84 & 0.09 & $\begin{array}{c}Z \\
\text { Chi-squared }\end{array}$ & $<0.01$ \\
& & & 8.38 & 0.04 \\
$S(\operatorname{chl} a)$ & & & $Z$ & \\
Zero-inflated & & & -2.20 & 0.03 \\
$C$ & -4.11 & 1.87 & 2.32 & 0.02 \\
$\delta_{2}$ & 4.32 & 1.86 & & \\
\hline
\end{tabular}

$\mathrm{p}$-value for each coefficient and smooth function was $<0.05$, suggesting significant relationships between the fish density and predictor variables. The mean fitted fish densities in each year and at each transect were close to the observed mean density in the northern region (Fig. 6a). However, the model fit in the southern region was not as good as in the northern region, especially for the transect values (Fig. 6b).

In the northern region, the predictor variables showed clear non-linear relationships with the salmon density (Fig. 7a). The relationship with temperature was especially non-linear, with an optimal tem- 

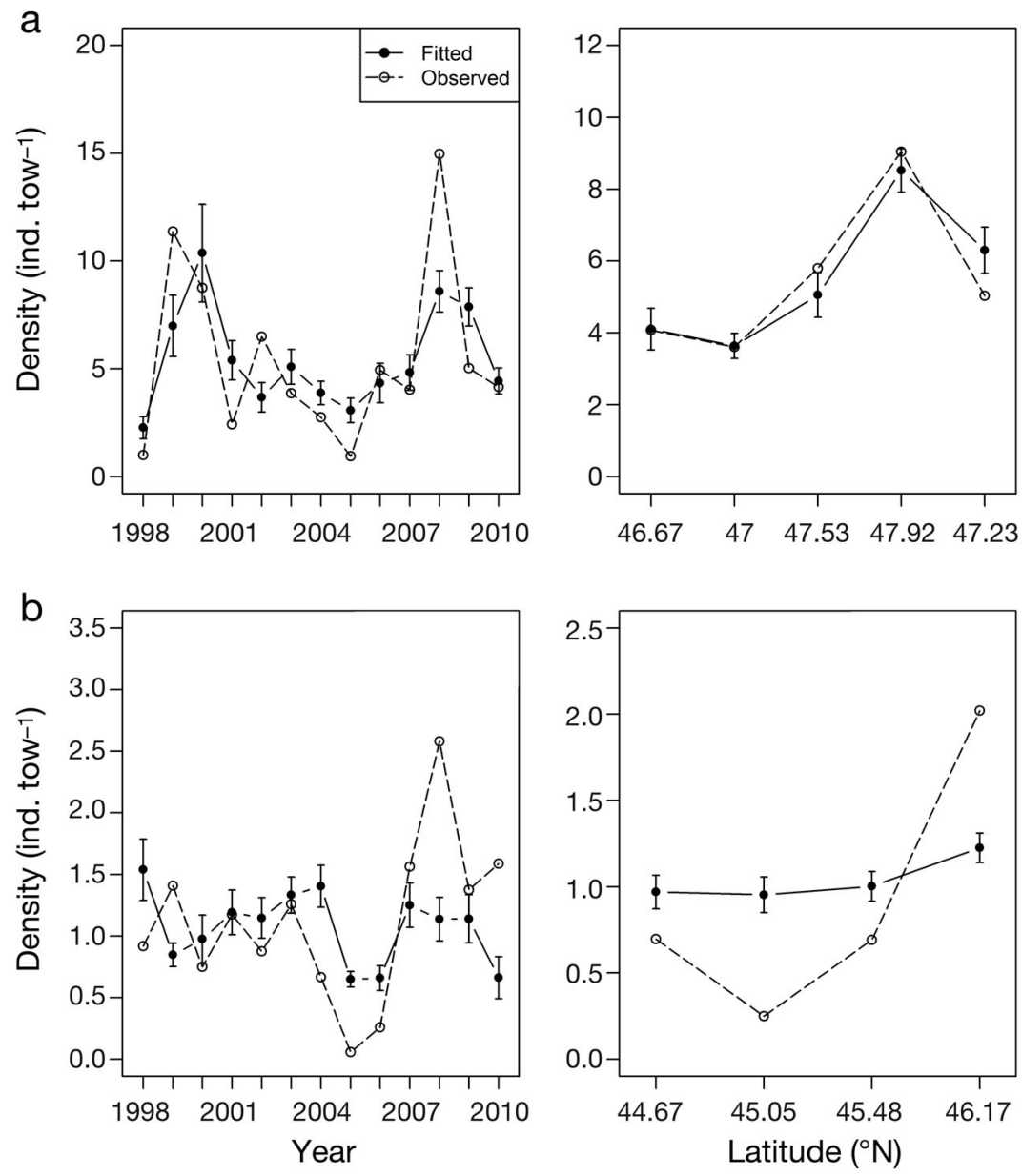

Fig. 6. Oncorhynchus tshawytscha. Comparison of observed and fitted mean $( \pm \mathrm{SE})$ density of juvenile spring Chinook salmon over time (left panel) and over transects (right panel) in the (a) northern and (b) southern regions

perature around $11.5^{\circ} \mathrm{C}$ (positive effect between $\sim 10$ and $13^{\circ} \mathrm{C}$ ). We also found that copepod biomass had an increasingly positive effect on salmon density. Chl a concentration mostly had a positive effect on salmon density ( 2 to $\left.8 \mathrm{mg} \mathrm{m}^{-3}\right)$, but a negative effect at higher concentrations. The interaction between spatial factors (longitude and latitude of the observations) showed a positive effect in the nearshore region, but a negative effect in the offshore region. In the southern region, salmon distribution was mainly affected by chl a concentration that mostly showed a positive effect on salmon density (more than $\sim 2 \mathrm{mg}$ $\mathrm{m}^{-3}$, Fig. 7b).

In the northern region, when the mean absolute effect of each predictor was compared, the spatial factors had the strongest effect on juvenile salmon distribution, followed by temperature, copepod biomass and chl $a$ (the effect of each variable varied somewhat among years) (Fig. 8).

\section{Relationship between alongshore ocean current and salmon distribution}

Alongshore ocean currents showed a strong annual variation pattern (Fig. 9a). For most years, the alongshore current changed its direction from northward (positive) to southward (negative) in April. The years 1998 and 2010 were not included in this analysis because the juvenile salmon survey in 1998 was incomplete (only a few locations in the northern region were sampled), which would have biased the estimation of fish densities ratio. The ocean current data were only available for the beginning of 2010. The ratio of fish densities in the northern and southern regions varied over time. The log-transformed ratio was positively correlated with April to June accumulation of alongshore ocean current speed (Fig. 9b), such that years with higher values of alongshore-cumulated current speed to the north resulted in a higher northto-south ratio of catches.

\section{DISCUSSION}

Our results show that the spatial distribution of yearling Chinook salmon Oncorhynchus tshawytscha is influenced by processes at different spatial scales. At a regional scale, the difference between north and south is related to alongshore water movement, a proxy for large-scale process. At a sub-regional scale, the spatial distribution can shift interannually due to differences in aspects of habitat quality (as indexed by temperature, chl a concentration and copepod biomass). Climate change and large ocean conditions can influence the variation of regional and local physical and biological processes (Chhak et al. 2009). For example, the PDO can lead to variation in alongshore water movement $(\mathrm{Bi}$ et al. 2011b, Keister et al. 2011), water temperature and nutrient composition in local waters of the Northeast Pacific (Chhak \& Lorenzo 2007), copepod community structure (Hooff \& Peterson 2006) and salmon abundance (Mantua et al. 1997, Peterson \& Schwing 2003). These effects can propagate up the food web and likely have significant impacts on fish abundance and 
a
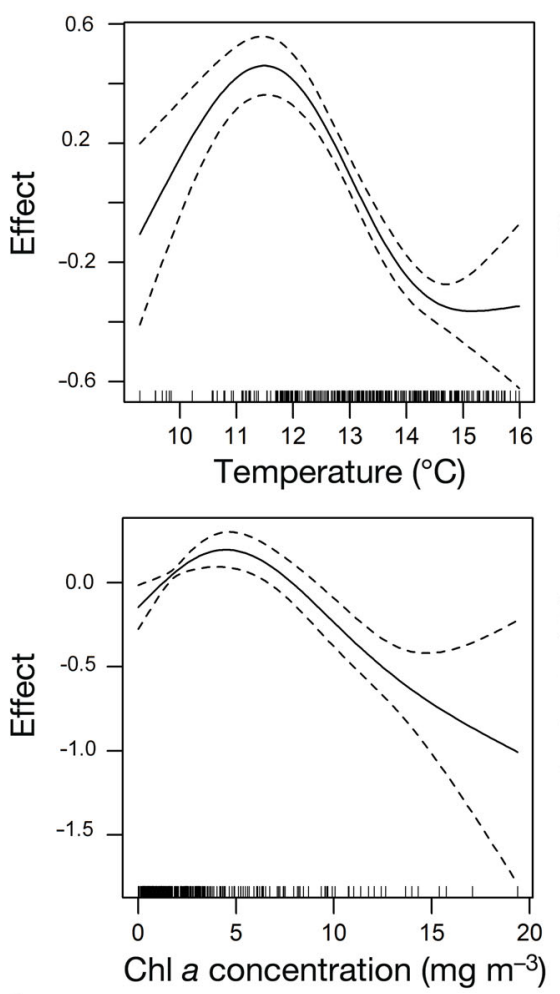

b

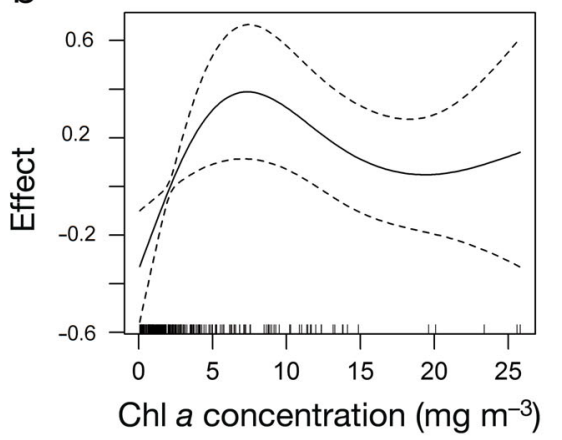

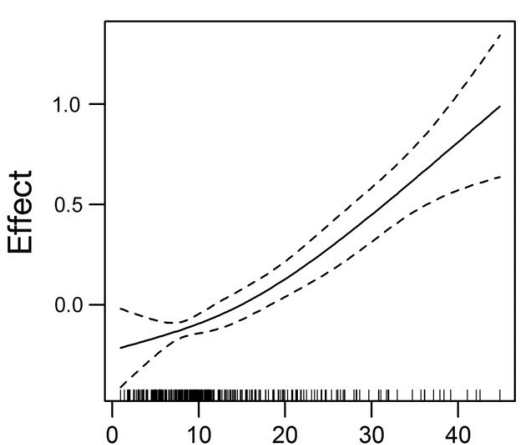

Copepods biomass $\left(\mathrm{mg} \mathrm{m}^{-3}\right)$

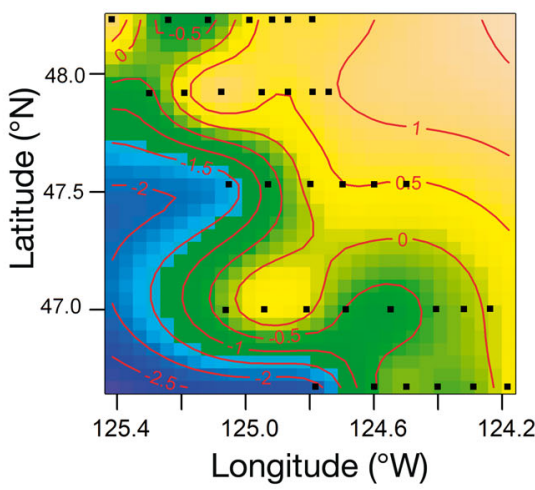

Fig. 7. Oncorhynchus tshawytscha. Effects (i.e. estimates of the smoothing functions) of predictor variables from the COZIGAM (constrained zero-inflated generalized additive model) on salmon density in the (a) northern and (b) southern regions. Dashed line: $95 \%$ confidence interval of the fitted values models (Bi et al. 2007, 2008). In the present study, we found that a linear model might underestimate the complex relationships within the study area. For example, a dome-shaped relationship between temperature and yearling Chinook salmon density potentially reflects the optimum temperature range for yearling Chinook salmon. Similar results were found for copepod biomass and chl a concentration. However, the relationship between chl a concentration and yearling Chinook abundance is puzzling. Previous studies have suggested that high chl a concentration indicated high production of all trophic levels including the small fish and krill upon which salmon fed (Ware \& Thomson 2005). In the present study, chl a concentration showed mostly a positive effect on salmon abundance, which is consistent with previous studies, but only at comparatively low concentrations; in contrast, chl a concentration showed a negative effect on salmon abundance when the concentration was higher than $\sim 8 \mathrm{mg} \mathrm{m}^{-3}$, north of the Columbia River mouth. This suggests that a high chl a concentration (and the associated high turbidity) has adverse effects on juvenile salmon, perhaps limiting the ability of salmon to find prey and, in turn, causing them to leave such areas and seek less turbid waters.

distribution. Our study also supports the findings that both large-scale and local factors control temporal and spatial variation of salmon density, which is critical in order to study relationships between ocean conditions, pelagic food webs and salmon.

The relationships between juvenile spring Chinook salmon density and environmental factors at a local scale were non-linear and complex. For example, in 2005, the mean water temperature was the highest during the survey period $\left(14.9^{\circ} \mathrm{C}\right)$, and the juvenile salmon density was very low both in the northern (0.95 ind. tow ${ }^{-1}$ ) and southern regions (0.06 ind. tow $^{-1}$ ). By contrast, in 2008, the water temperature was the lowest $\left(11.6^{\circ} \mathrm{C}\right)$, and the juvenile salmon density was the highest both in the northern (15.0 ind. tow $^{-1}$ ) and southern regions ( 2.6 ind. tow $\left.{ }^{-1}\right)$. Previous studies described these relationships using linear
The juvenile Chinook salmon distribution showed an apparent spatial difference in northern and southern regions, with the Washington coast (northern region) usually providing better habitat than the Oregon coast (southern region), such as lower water temperature, a broad shelf with sluggish circulation and higher productivity (Hickey \& Banas 2008, Peterson et al. 2010). Based on the directional Moran's I (Fig. 5), the global Moran's I was mainly determined by the south-north directional Moran's I. The higher Moran's I values indicate that the fish were more aggregated in the north. Similarly, the factors correlated in a south-north direction, which may affect juvenile salmon distribution greatly, were temperature and alongshore ocean current. Alternatively, Peterson et al. (2010) suggested the hypotheses that spatial variations in the distribution 


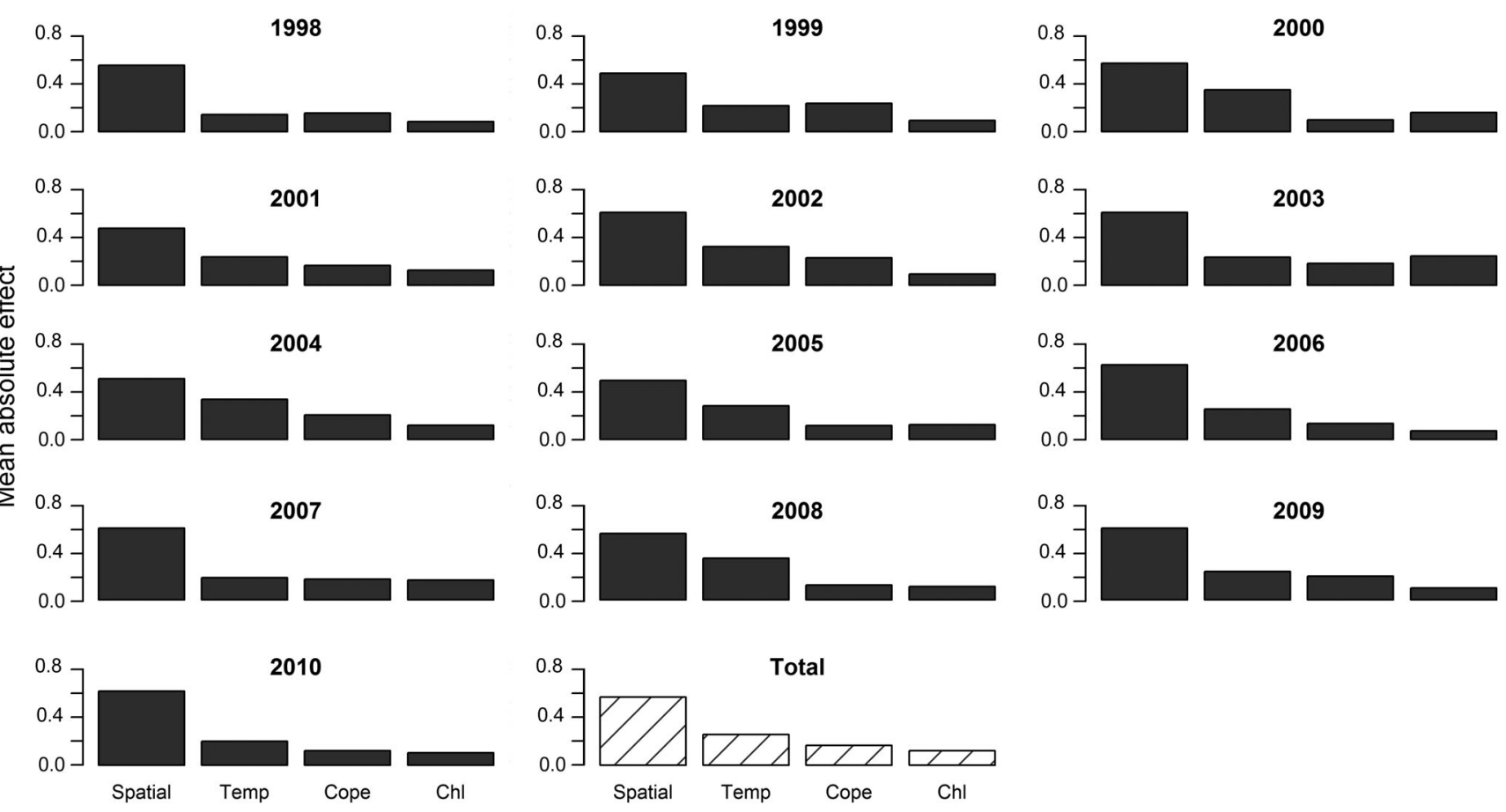

Fig. 8. Oncorhynchus tshawytscha. Comparison of mean absolute effects of predictor variables from the COZIGAM over time in the northern region. Spatial: spatial factors; Temp: temperature; Cope: copepod biomass; Chl: chl a

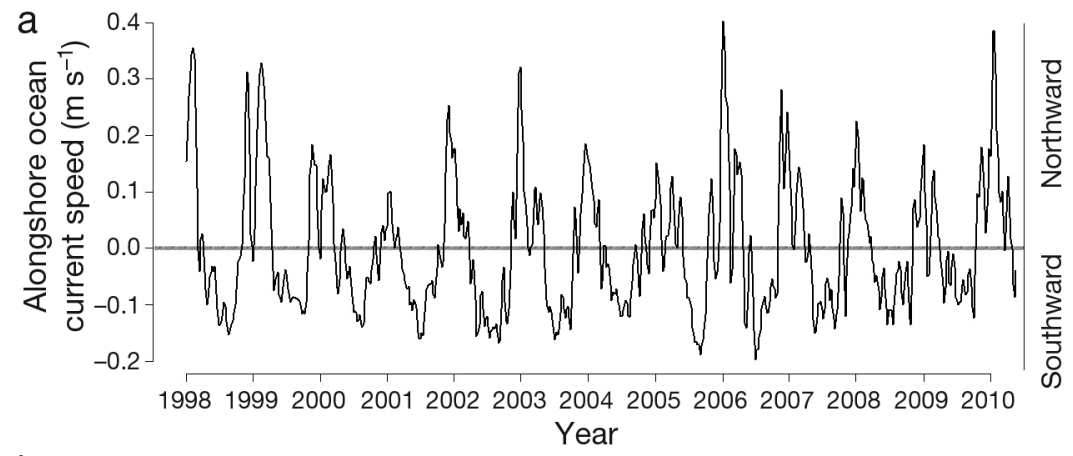

Fig. 9. Oncorhynchus tshawytscha. (a) Alongshore ocean current speed variation over time and (b) comparison of mean densities of juvenile spring Chinook salmon in the northern and southern regions (left panel) and relationship between the logtransformed density ratio and accumulated alongshore ocean current from April to June (right panel)

b
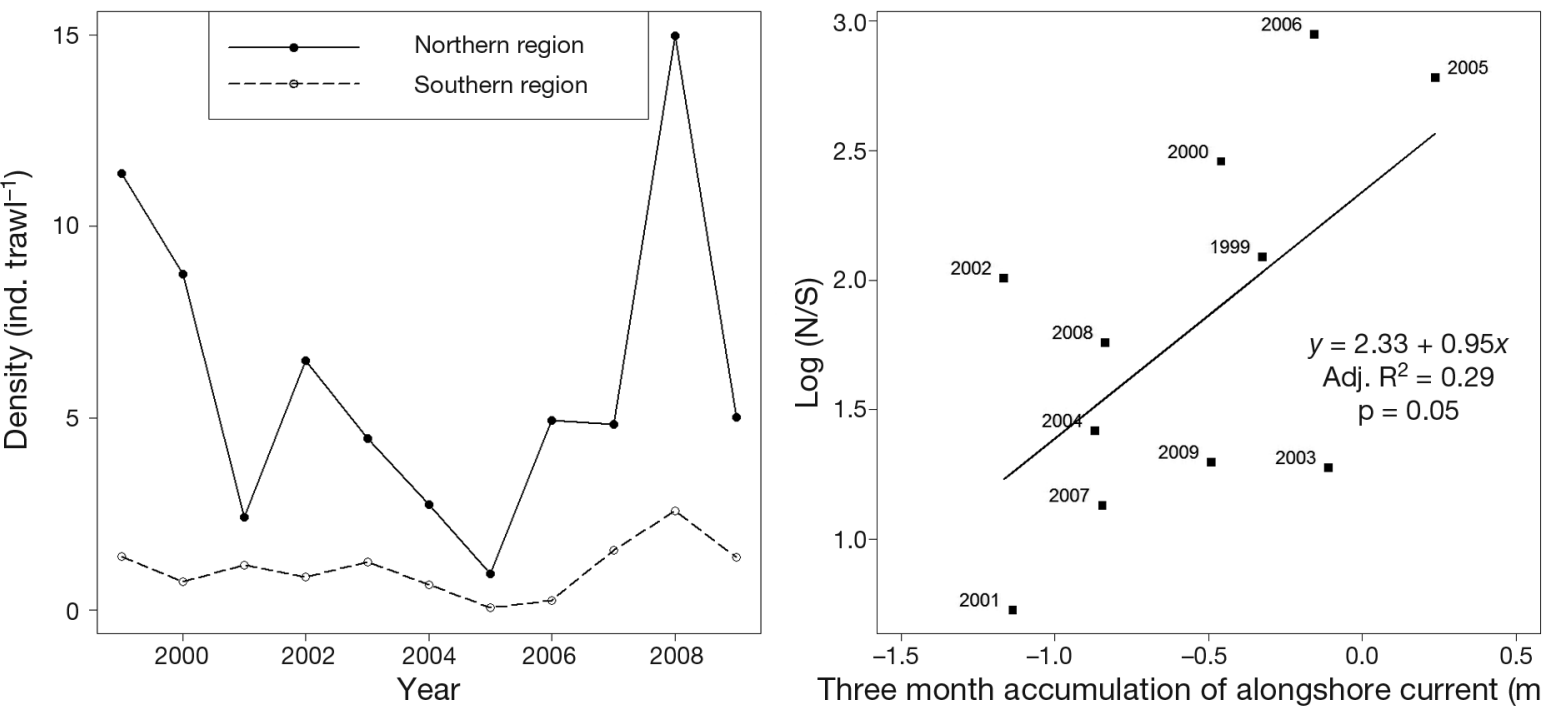

Three month accumulation of alongshore current $\left(\mathrm{m} \mathrm{s}^{-1}\right)$ 
patterns of juvenile salmon were related to the presence of submarine canyons along the Washington coast, features which are absent off Oregon (Hickey 1995). These canyons may offer better habitats to juvenile salmon because canyons may concentrate krill, an idea suggested by Peterson et al. (2010). In the present study, the effect of spatial factors was the most important factor, and the overall spatial structure north of the Columbia River-derived from the COZIGAM model-was consistent with the canyon hypothesis. In the southern region, the spatial factor did not have a significant effect. However, the canyon hypothesis cannot address the interannual variation in the difference between the north and south, because canyons are fixed geographic features that, of course, do not show interannual variation.

Juvenile spring Chinook salmon density can be impacted by the alongshore ocean currents. The higher ratio between the densities in the northern versus the southern region could be caused by relatively high abundance in the north (e.g. 1999 and 2000) and/or relatively low abundance in the south (e.g. 2005 and 2006). The lower ratio could be caused by lower abundance in the north (e.g. 2001) and/or higher abundance in the south (e.g. 2008). The interannual variation between the density in the north and south could also be a function of differential mortality and migration behavior in the 2 different regions. Trudel et al. (2009) reported that juvenile Chinook salmon migrated faster in the northern than in the southern region. The differential mortality in the north and south could be caused by the fact that ocean conditions may influence the Washington coast differently from the Oregon coast. Previous studies have shown that stronger southward alongshore ocean currents enhanced the biomass of cold-water copepods (Bi et al. 2011b, Keister et al. 2011). The cold-water copepods are from the coastal Gulf of Alaska and rich in lipids which, in turn, results in a food chain with relatively higher lipid (thus bioenergetics) content. Given that salmon are a lipid-rich species with some of the highest values of omega-3 fatty acids of any marine fish, it is reasonable to assume that their growth and survival are a function of the bioenergetic content of the food chain (Hooff \& Peterson 2006, Lee et al. 2006). However, in other years (e.g. 2002), a southward alongshore current did not lead to higher abundance in the south. Further investigations are needed in the future on how ocean conditions influence the survival and migration of juvenile salmon off Washington and Oregon differently.
The model fit of the COZIGAM was good compared to the observed data. However, the observed fish densities were much lower than modeled densities in 2005 and higher in 2008 than the average level. Local environmental factors could not explain this observation completely, suggesting that largescale ocean conditions, such as the PDO and the El Niño Southern Oscillation, may contribute to this distribution pattern. However, the mechanism of their contributions is still unknown. It seems that large-scale ocean conditions will affect local environmental factors and then further influence juvenile salmon distribution. For example, in 2008, the PDO had extraordinarily negative values, the water temperature was very low during the juvenile salmon survey period, and many more juvenile salmon were caught in that year. In comparison, in 2005, a time when the PDO was positive, the lowest densities were observed. The low densities apparently were related to warm temperatures in May and June when salmon first entered the sea. The warm conditions indicate a poor feeding environment, as suggested by the extremely low biomass of northern lipid-rich copepod species in May to July (Kosro et al. 2006, Mackas et al. 2006).

One of the distinctive characteristics of the juvenile Chinook salmon survey data was the prevalence of zero catches. Additionally, the percentage of non-zero catches also changed over time. Only $22.2 \%$ of the sampling locations (36 sampled stations) had non-zero catches in 2005; however, $83.7 \%$ of the sampling locations (49 sampled stations) had non-zero catches in 2008. If we ignored this zero-inflated problem and fitted a standard Poisson model, the estimated parameters could be biased (Welsh et al. 1996). The COZIGAM is a 2stage approach to solve this problem. This model was able to fit the survey data appropriately and correctly reflect the interannual and spatial distribution patterns of juvenile spring Chinook salmon. We found that the probability of a zero catch belonging to the zero-inflation part of the model could be explained by water temperature and copepod density in the northern region and $\mathrm{chl} a$ concentration in the southern region. This result was consistent with the findings of a previous study (Bi et al. 2008). However, a non-linear relationship may be a more reasonable explanation for the variation in the zeroinflation probability. This model will be helpful for further study of salmon distribution, because water temperature and chlorophyll data can be obtained from satellite surveys, allowing one to model on much finer scales. 
Acknowledgements. This synthesis research was supported by NASA. Data collection was funded by the Bonneville Power Administration. We also acknowledge the people who contributed substantially to data collection and processing: B. Beckman, P. Bentley, C. Bucher, R. Emmett, J. Fisher, T. Guy, S. Hinton, C. Morgan, L. Weitkamp and J. Zamon.

\section{LITERATURE CITED}

Arab A, Wildhaber ML, Wikle CK, Gentry CN (2008) Zeroinflated modeling of fish catch per unit area resulting from multiple gears: application to channel catfish and shovelnose sturgeon in the Missouri River. N Am J Fish Manag 28:1044-1058

Beale CM, Lennon JJ, Yearsley JM, Brewer MJ, Elston DA (2010) Regression analysis of spatial data. Ecol Lett 13: 246-264

Bi H, Ruppel RE, Peterson WT (2007) Modeling the pelagic habitat of salmon off the Pacific Northwest (USA) coast using logistic regression. Mar Ecol Prog Ser 336:249-265

Bi H, Ruppel RE, Peterson WT, Casillas E (2008) Spatial distribution of ocean habitat of yearling Chinook (Oncorhynchus tshawytscha) and coho (Oncorhynchus kisutch) salmon off Washington and Oregon, USA. Fish Oceanogr 17:463-476

> Bi H, Peterson WT, Lamb J, Casillas E (2011a) Copepods and salmon: characterizing the spatial distribution of juvenile salmon along the Washington and Oregon coast, USA. Fish Oceanogr 20:125-138

Bi H, Peterson WT, Strub PT (2011b) Transport and coastal zooplankton communities in the northern California Current system. Geophys Res Lett 38:L12607, doi:10.1029/ 2011GL047927

Brodeur RD, Fisher JP, Teel DJ, Emmett RL, Casillas E, Miller TW (2004) Distribution, growth, condition, origin, and associations of juvenile salmonids in the northern California Current. Fish Bull 102:25-46

Chhak KC, Lorenzo ED (2007) Decadal variations in the California Current upwelling cells. Geophys Res Lett 34: L14604, doi:10.1029/2007GL030203

Chhak KC, Lorenzo ED, Schneider N, Cummins PF (2009) Forcing of low-frequency ocean variability in the northeast Pacific. J Clim 22:1255-1276

Ciannelli L, Fauchald P, Chan KS, Agostini VN, Dingsor GE (2008) Spatial fisheries ecology: recent progress and future prospects. J Mar Syst 71:223-236

> Cunningham RB, Lindenmayer DB (2005) Modeling count data of rare species: some statistical issues. Ecology 86 : 1135-1142

Dahl J, Dannewitz J, Karlsson L, Petersson E, Löf A, Ragnarsson B (2004) The timing of spawning migration: implications of environmental variation, life history, and sex. Can J Fish Aquat Sci 82:1864-1870

Friedland KD (1998) Ocean climate influences on critical Atlantic salmon (Salmo salar) life history events. Can J Fish Aquat Sci 55(Suppl 1):119-130

Hall DB (2000) Zero-inflated Poisson and binomial regression with random effects: a case study. Biometrics 56: 1030-1039

Hickey BM (1995) Coastal submarine canyons. In: Muller P, Henderson D (eds) Proceedings of the University of Hawaii 'Aha Huliko'a Workshop on flow topography interactions. SOEST Special Publication, University of Hawaii, Honolulu, HI, p 95-110
Hickey BM, Banas NS (2008) Why is the northern end of the California Current system so productive? Oceanography (Wash DC) 21:90-107

> Hinch SG, Healey MC, Diewert RE, Thomson KA, Hourston R, Henderson MA, Juanes F (1995) Potential effects of climate change on marine growth and survival of Fraser River sockeye salmon. Can J Fish Aquat Sci 52: 2651-2659

> Hinke JT, Foley DG, Wilson C, Watters GM (2005) Persistent habitat use by Chinook salmon Oncorhynchus tshawytscha in the coastal ocean. Mar Ecol Prog Ser 304:207-220

> Hooff RC, Peterson WT (2006) Copepod biodiversity as an indicator of changes in ocean and climate conditions of the northern California Current ecosystem. Limnol Oceanogr 51:2607-2620

Jonsson B, Jonsson N (2004) Factors affecting marine production of Atlantic salmon (Salmo salar). Can J Fish Aquat Sci 61:2369-2383

Keister JE, Lorenzo EDI, Morgan CA, Combes V, Peterson WT (2011) Zooplankton species composition is linked to ocean transport in the northern California Current. Glob Change Biol 17:2498-2511

> Kendall NW, Dittman AH, Quinn TP (2010) Comparative maturation schedules of two Columbia River sockeye salmon Oncorhynchus nerka populations. Endang Species Res 13:51-61

Kosro PM, Peterson WT, Hickey BM, Shearman RK, Pierce SD (2006) Physical vs. the biological spring transition: 2005. Geophys Res Lett 33:L22S03, doi:10.1029/2006GL 027072

Lambert D (1992) Zero-inflated Poisson regression, with an application to detects in manufacturing. Technometrics 34:1-14

Latimer AM, Wu S, Gelfand AE, Silander JA (2006) Building statistical models to analyze species distribution. Ecol Appl 16:33-50

Lee RF, Hagen W, Kattner G (2006) Lipid storage in marine zooplankton. Mar Ecol Prog Ser 307:273-306

Liu H, Chan KS (2010) Introducing COZIGAM: an R package for unconstrained and constrained zero-inflated generalized additive model analysis. J Stat Softw 35:1-26

Logerwell EA, Mantua N, Lawson PW, Francis RC, Agostini VN (2003) Tracking environmental processes in the coastal zone for understanding and predicating Oregon coho (Oncorhynchus kisutch) marine survival. Fish Oceanogr 12:554-568

> Mackas DL, Peterson WT, Ohman MD, Lavaniegos BE (2006) Zooplankton anomalies in the California Current system before and during the warm ocean conditions of 2005. Geophys Res Lett 33:L22S07, doi:10.1029/2006GL 027930

Mantua NJ, Hare SR, Zhang Y, Wallace JM, Francis RC (1997) A Pacific interdecadal climate oscillation with impacts on salmon production. Bull Am Meteorol Soc 78: 1069-1079

> Maunder MN, Punt AE (2004) Standardizing catch and effort data: a review of recent approaches. Fish Res 70: 141-159

Metcalfe NB (1998) The interaction between behavior and physiology in determining life history patterns in Atlantic salmon (Salmo salar). Can J Fish Aquat Sci 55(Suppl 1): 93-103

> Minami M, Lennert-Cody CE, Gao W, Roman-Verdesoto M (2007) Modeling shark bycatch: the zero-inflated negative binomial regression model with smoothing. Fish Res 
84:210-221

Moran PAP (1950) Notes on continuous stochastic phenomena. Biometrika 37:17-23

Nickelson TE (1986) Influences of upwelling, ocean temperature, and smolt abundance on marine survival of coho salmon (Oncorhynchus kisutch) in the Oregon Production Area. Can J Fish Aquat Sci 43:527-535

Pearcy WG (1992) Ocean ecology of North Pacific salmonids. University of Washington Press, Seattle, WA

Pearcy WG, Fisher JP (1990) Distribution and abundance of juvenile salmonids off Oregon and Washington, 19811985. NOAA Tech Rep 93:1-83, WA

$>$ Peterson WT, Schwing FB (2003) A new climate regime in northeast Pacific ecosystems. Geophys Res Lett 30, doi: 10.1029/2003GL017528

Peterson WT, Morgan CA, Fisher JP, Casillas E (2010) Ocean distribution and habitat associations of yearling coho (Oncorhynchus kisutch) and Chinook (O. tshawytscha) salmon in the northern California Current. Fish Oceanogr 19:508-525

Pool S, Reese D, Brodeur R (2012) Defining marine habitat of juvenile Chinook salmon, Oncorhynchus tshawytscha, and coho salmon, O. kisutch, in the northern California Current system. Environ Biol Fishes 93:233-243

Richards SA (2008) Dealing with overdispersed count data in applied ecology. J Appl Ecol 45:218-227

Rupp DE, Wainwright TC, Lawson PW, Peterson WT (2012) Marine environment-based forecasting of coho salmon (Oncorhynchus kisutch) adult recruitment. Fish Oceanogr 21:1-19

Saraceno M, Strub PT, Kosro PM (2008) Estimates of sea surface height and near-surface alongshore coastal currents

Editorial responsibility: Jake Rice,

Ottawa, Ontario, Canada from combinations of altimeters and tide gauges. J Geophys Res 113:C11013, doi:10.1029/2008JC004756

- Stoner A, Manderson J, Pessutti J (2001) Spatially explicit analysis of estuarine habitat for juvenile winter flounder: combining generalized additive models and geographic information systems. Mar Ecol Prog Ser 213: 253-271

Swartzman G, Huang C, Kaluzny S (1992) Spatial analysis of Bering Sea groundfish survey data using generalized additive models. Can J Fish Aquat Sci 49:1366-1378

Trudel M, Fisher J, Orsi JA, Morris JFT and others (2009) Distribution and migration of juvenile Chinook salmon derived from coded wire tag recoveries along the continental shelf of western North America. Trans Am Fish Soc 138:1369-1391

Tucker S, Trudel M, Welch DW, Candy JR and others (2011) Life history and seasonal stock-specific ocean migration of juvenile Chinook salmon. Trans Am Fish Soc 140: 1101-1119

- Ware DM, Thomson RE (2005) Bottom-up ecosystem tropic dynamics determine fish production in the Northeast Pacific. Science 308:1280-1284

> Welsh AH, Cunningham RB, Donnelly CF, Lindenmayer DB (1996) Modelling the abundance of rare species: statistical models for counts with extra zeros. Ecol Model 88: 297-308

Wood SN (2006) Generalized additive models: an introduction with R. Chapman \& Hall/CRC, Boca Raton, FL

Yu H, Jiao Y, Winter A (2011) Catch-rate standardization for yellow perch in Lake Erie: a comparison of the spatial generalized linear model and the generalized additive model. Trans Am Fish Soc 140:905-918

Submitted: October 17, 2011; Accepted: June 25, 2012 Proofs received from author(s): September 19, 2012 